\title{
Acute left-sided colonic diverticulitis: clinical expressions, therapeutic insights, and role of computed tomography
}

This article was published in the following Dove Press journal:

Clinical and Experimental Gastroenterology

18 August 2016

Number of times this article has been viewed

\section{Patrick Ambrosetti \\ Department of Surgery, Clinique Générale Beaulieu, Geneva, Switzerland}

Correspondence: Patrick Ambrosetti Department of Surgery, Clinique Générale Beaulieu, Ch Beau-Soleil, 1205

Geneva, Switzerland

$\mathrm{Tel}+4 \mid 228300520$

Fax +4I 228302343

Email P_ambrosetti@bluewin.ch

\begin{abstract}
The diagnostic approach of patients with suspected acute diverticulitis remains debated. On the one hand, a scoring system with the best predictive value in diagnosing acute diverticulitis has been developed in order to reduce the use of computed tomography (CT) scan, while, on the other hand, patients with a high probability of acute diverticulitis should benefit from CT scan from a clinical viewpoint, ensuring that they will receive the most appropriate treatment. The place and classification of CT scan for acute diverticulitis need to be reassessed. If the management of uncomplicated acute diverticulitis, abscess, and fecal peritonitis is now well codified, urgent surgical or medical treatment of hemodynamically stable patients presenting with intraperitoneal air or fluid without uncontrolled sepsis is still under discussion. Furthermore, the indications for laparoscopic lavage are not yet well established. It is known for years that episode(s) of acute uncomplicated diverticulitis may induce painful recurrent bowel symptoms, known as symptomatic uncomplicated diverticular disease and irritable bowel syndrome-like diverticular disease. These two clinical expressions of diverticular disease, that may darken quality of life, are treated medically aimed at symptom relief. The possible place of surgery should be discussed. Clinical and CT scan classifications should be separated entities.
\end{abstract}

Keywords: diverticulitis, urgent treatment, chronic symptoms, clinical and CT scan classifications

\section{Introduction}

The prevalence of diverticulosis is $<20 \%$ in people $<40$ years of age compared to $60 \%$ in people $>70$ years of age. ${ }^{1}$ Acute diverticulitis occurs in $\sim 4 \%$ of patients with diverticulosis, and $30 \%$ of these patients will have complicated diverticulitis (persisting or recurring diverticulitis). ${ }^{2}$ After recovery from a first episode of diverticulitis, $16 \%-19 \%$ of patients will have recurrence after 9 years and 15 years. ${ }^{3,4}$ Diverticulitis is the most frequent surgically treated disease after cancer in modern Western societies. A nationwide inpatient sample study in the US has shown that diverticulitis-associated hospitalizations between 1998 and 2005 have steeply risen, especially in young adults. ${ }^{5}$

If management of acute diverticulitis has undergone meaningful changes over the past decade, the majority of evidence is currently of poor quality. ${ }^{6}$ The aim of this study is to focus on other issues that are also still debated: the place of computed tomography (CT) scan, the role of laparoscopic lavage for colonic perforation, and the surgical indications for patients with chronic symptoms. 


\section{Present role of CT scan CT scan as a diagnostic tool}

The diagnostic approach of patients with suspected acute diverticulitis remains debated. ${ }^{7}$ Andeweg et $a l^{8}$ developed a scoring system with the best predictive value for diagnosing acute diverticulitis, in order to reduce the use of CT scan. In contrast, Karidis et $\mathrm{al}^{9}$ stated that patients with a high probability of acute diverticulitis constitute a group that will mostly benefit from CT scan from a clinical viewpoint, ensuring that they will receive the most appropriate treatment. Thus, the role of CT scan for acute diverticulitis needs to be reassessed.

The central place of CT to diagnose and evaluate the severity of acute left-sided colonic diverticulitis has now been largely proven ${ }^{10,11}$ together with a better performance in the detection of complicated diverticulitis compared with watersoluble contrast enema. ${ }^{12}$ Should we do CT for every patient suspected to have acute diverticulitis? The last recommendation of the American Society of Colon and Rectal Surgery proposed to realize "abdominal radiograph" in selected clinical scenarios. ${ }^{13}$ This statement was based on a retrospective study of 124 patients with a CT-proven acute diverticulitis. A nomogram was constructed based on seven independent variables (age $>50$ years, previous episodes of acute diverticulitis, lower left abdominal pain, aggravation of pain on movement, no vomiting, lower left abdominal tenderness, and C-reactive protein $[\mathrm{CRP}]>50 \mathrm{mg} / \mathrm{L}$ ) that were independent predictors of acute diverticulitis, with a diagnostic accuracy of $86 \%$. The authors stated that additional imaging could be omitted in case of a high chance of acute left-sided colonic diverticulitis based on the nomogram. ${ }^{8}$ Another study explored a clinical decision rule to diagnose acute diverticulitis that was used to select patients in whom additional imaging to diagnose acute diverticulitis could also be omitted. Three features (isolated tenderness in the left-lower quadrant, absence of vomiting, and $\mathrm{CRP}>50 \mathrm{mg} / \mathrm{L}$ ) had the best positive predictive value. Of 30 patients having all three features, 29 had a final diagnosis of acute diverticulitis (positive predictive value of $97 \%$ ). In patients without these three features, imaging is required. ${ }^{14}$ A third study, comparing acute diverticulitis (145 patients) with nonspecific abdominal pain (1,142 patients), found bioclinical features that can differentiate acute diverticulitis from nonspecific abdominal pain. ${ }^{15}$ An external validation of the tools including these previous three studies was proposed to select patients in whom additional imaging to diagnose acute diverticulitis could be omitted. ${ }^{16}$ The relevance of these studies has to be taken with caution for the following reasons: the number of patients in each study is relatively low
(124 patients, ${ }^{8} 80$ patients, ${ }^{14}$ and 58 patients ${ }^{15}$ ), and clinical signs and value of CRP are not highly discriminating parameters. With regard to clinical signs, Longstreth et al, ${ }^{17}$ in their retrospective study of 741 patients, comparing CT classifications (1, nondiagnostic; 2 , moderate; 3 , severe) with clinical and laboratory features, found that $74.7 \%$ of the 92 patients with CT-severe diverticulitis had only lower abdominal pain. Two studies found that the accuracy of clinical evaluation for colonic diverticulitis is low, with a sensitivity of $64 \%{ }^{9}$ and $68 \% .{ }^{18}$ Besides, inclusion of a more objective parameter, CRP $>50 \mathrm{mg} / \mathrm{L}$ could also be argued. Käser et al ${ }^{19}$ found that of 46 patients who had a CT with a CRP $<50 \mathrm{mg} / \mathrm{L}, 12(26 \%)$ had a colonic perforation, while van de Wall et $\mathrm{al}^{20}$ reported that patients with a CRP of $25 \mathrm{mg} / \mathrm{L}$ had $15 \%$ chance of having complicated diverticulitis. Finally, Vennix et a ${ }^{21}$ published a review of evidence and consensus on diverticulitis analyzing six guidelines: the American Society of Colon and Rectal Surgeons (ASCRS), 2006, the Association of Coloproctology of Great Britain and Ireland (ACPGBI), 2011, the Association of Surgeons of The Netherlands (ASN), 2012, the Danish Surgical Society (DSS), 2011, the European Association for Endoscopic Surgery (EAES), 2011, and the World Society for Emergency Surgery (WSES), 2011. The authors reported that the ASN and DSS guidelines, based on the study of Laméris et $\mathrm{al}^{14}$ that reported only $25 \%$ of patients who had all three features (abdominal pain in the left lower quadrant, CRP $>50 \mathrm{mg} / \mathrm{L}$, and absence of vomiting), concluded that clinical assessment alone for the diagnosis of diverticulitis is insufficiently precise. ${ }^{21}$

In fact, if CT is definitely considered as the best tool to diagnose acute diverticulitis, its place at present time is not clearly stated since a majority of patients with clinical (left-lower abdominal pain) and biological assessment (high white blood cell count) compatible with acute uncomplicated diverticulitis will not have a CT. The study of O'Connor et $\mathrm{al}^{22}$ reporting on 3,396 patients with the diagnosis of acute diverticulitis found that the use of CT for the 2,576 outpatients (outpatient Clinic) compared with 820 inpatients (emergency room) was quite low (14\% vs $85 \%$ ).

\section{CT scan usefulness}

$\mathrm{CT}$ is definitely the best tool today for the physician to be in a position to apply the most appropriate treatment for patients with a first episode of acute colonic diverticulitis and to evaluate the risk of recurrence for the patients who were responding favorably to a nonoperative treatment of their first attack. The proposed treatment of an acute diverticulitis depends on the physiological state of the patient, the physical 
examination, the inflammatory indexes, and the CT scan images. In this situation, the findings of CT are the essential keys for the decision of a nonoperative management of the disease. In hemodynamically stable patients with colonic perforation location and size of peritoneal air, intraperitoneal fluid, and location and size of abscess(es) reported by CT, together with clinical appreciation and biological examinations, will guide the physician to identify patients who can be treated nonoperatively and patients who need an urgent surgical treatment. The quality of CT (intra-venous and rectal contrast) is very important, first to propose surgery with sigmoidectomy in case of leakage of contrast in the abdominal cavity and second to suspect a cancer.

Findings of $\mathrm{CT}$ are also essential to inform patients of the risk of recurrence after a first episode of acute diverticulitis. Trenti et $\mathrm{al}^{23}$ studied prospectively 560 patients admitted for the first episode of acute diverticulitis confirmed by CT scan and treated conservatively. After a mean follow-up of $67.2 \pm 44.4$ months, the rate of recurrence was $14 \%$ after an uncomplicated diverticulitis and $17.6 \%$ after a complicated diverticulitis ( $P=0.321)$, and the risk of severe recurrence was statistically greater in the group with an initial complicated diverticulitis. ${ }^{23}$ In our series of 300 patients who were treated conservatively for their first episode of acute diverticulitis we found, after a median follow-up of 46 months, that the risk of recurrence of acute diverticulitis was statistically higher in patients with initial CT-severe diverticulitis (abscess and/or extraluminal contrast and/or extraluminal air), compared with patients with initial CT-moderate diverticulitis (47\% vs 19\%, $P<0.0001) .{ }^{24}$ Poletti et $\mathrm{al}^{25}$ found that abscess and pockets of extraintestinal gas $\geq 5 \mathrm{~mm}$ correlated with unfavorable outcome of nonoperative treatment. Shaik et al, ${ }^{26}$ using our CT classification, found that $12(55 \%)$ of the 22 surviving patients with CT-severe initial episode of acute diverticulitis were having later surgical treatment, compared with 23 $(13.6 \%)$ of the 169 patients with moderate disease $(P<0.001)$. Hall et $\mathrm{al}^{27}$ found that length of involved colon $>5 \mathrm{~cm}$ and retroperitoneal abscess were associated with diverticulitis recurrence. ${ }^{27}$ Buchs et $\mathrm{al}^{28}$ found that free air on initial CT was of borderline significance for the risk of recurrence.

Number, severity, and location of episode(s) of acute diverticulitis are essential keys to evaluate the place of elective surgery. Recently, Gervaz et $\mathrm{al}^{29}$ have found that in $35 \%$ of patients who had a recurrence after an initial uncomplicated sigmoiditis the diverticulitis will involve another segment of the left colon. Knowing that $93 \%$ of acute diverticulitis involve the sigmoid and the descending colon, this finding is very important to guide elective surgery that should ideally remove all the segments affected with diverticulitis. ${ }^{30}$

A review of six guidelines has been recently published and concluded that "clinical assessment is insufficiently precise" and "agreed on the need for imaging in addition to clinical diagnosis, for staging and other diagnosis, preferably by CT". ${ }^{21}$ Another radiological review focusing on the current role of CT arrived at the same conclusion. ${ }^{31}$

Then, considering the crucial and numerous roles of the CT scan (precise diagnosis/complicated vs uncomplicated diverticulitis/colonic location), it seems reasonable to propose a CT scan to all patients suspected to have an acute diverticulitis. There is no doubt that patients reporting episodes of CT-proven acute diverticulitis will give accurate findings to help indicate elective surgical treatment.

CT scan should not be anymore related to the surgical Hinchey's classification, which is now outdated. ${ }^{32}$ For instance, Hinchey 3 or 4 (generalized purulent peritonitis or fecal peritonitis) cannot be directly translated by CT since free intraperitoneal fluid is not pathognomonic for Hinchey 3 or 4 . To illustrate this fact, Gielens et al, ${ }^{33}$ assessing the accuracy of preoperative staging of perforated diverticulitis by CT for 75 patients, found that accuracy of Hinchey's classification is not very high since in $43 \%$ of cases Hinchey 3 's perforated diverticulitis was falsely classified as Hinchey 1 or 2 by $\mathrm{CT}$. The use of rectal contrast increased the accuracy of CT scanning to $11 \%$.

Consequently, CT scan has to be completely descriptive, taking into consideration the details of all the signs that might play a role in the evaluation of acute diverticulitis. The punctilious analysis of the CT images will considerably help the physician to make the best therapeutic choice (oral antibiotic therapy vs no antibiotic therapy/intravenous antibiotic therapy/percutaneous drainage of abscess/conservative or surgical treatment of colonic perforation). To be the most accurate descriptive imaging, CT should be done within 48 hours after onset of the abdominal symptoms. Intravenous and rectal contrast will considerably enhance the performance of the quality of the lecture. ${ }^{34-40}$ The precise lecture of the CT scan classifies acute diverticulitis into uncomplicated and complicated diverticulitis. In order to reach this position, the following revision of CT scan is proposed (Table 1).

\section{The role of colonoscopy or CT colonography after acute diverticulitis}

The role of colonoscopy is now changing and seems to be important for patients after an acute complicated episode of diverticulitis, for patients with persistent symptoms, and 
Table I Revised CT classification

\begin{tabular}{ll}
\hline Classification & CT performed with IV-contrast and water- \\
& soluble rectal contrast \\
\hline I. & Uncomplicated acute diverticulitis \\
& Site: proximal or distal descending colon/proximal or \\
& distal sigmoid \\
& Length of inflammation (cm) \\
& Maximal thickness (cm) \\
& Inflammation of pericolic fat (phlegmon) \\
& Complicated acute diverticulitis (classification I + one \\
& or more of the following findings) \\
& Abscess(es): mesocolic/pelvic/abdominal (maximum \\
& diameter in cm) \\
& Contrast extravasation: mesocolic/peritoneal \\
& Free air: mesocolic/pericolic/at distance (maximum \\
& diameter in cm) \\
& Free fluid: mesocolic/peritoneal (volume in mL) \\
& Complicated chronic diverticulitis \\
& Fistula \\
Stenosis
\end{tabular}

Abbreviation: CT, computed tomography.

for patients aged 50 years or older. ${ }^{41}$ Most practice guidelines advise performing colonoscopy after an episode of acute diverticulitis, but this statement lacks clear scientific evidence. $^{31}$

Recently, Flor et $\mathrm{al}^{42}$ proposed a CT colonography as a prognostic tool after recovering from an episode of acute diverticulitis. A diverticular disease severity score based on maximum sigmoid wall thickness and minimum lumen diameter showed a correlation with the risk of undergoing surgery and found $11 \%$ of relevant additional findings. A significant correlation ( $P=0.022)$ between diverticular disease severity score and the final clinical outcome (good health/mild typical pain/recurrence) was found. This study is limited by a small sample size (46 patients) and by the fact that no detailed comparison between the initial CT at the time of the acute event and $\mathrm{CT}$ colonography has been done. If it is too early to propose this later radiological examination for all patients after an acute diverticulitis, it could really be interesting for selected patients (complicated diverticulitis/residual symptoms/age $>50$ years).

Tursi et al ${ }^{43}$ proposed an endoscopic classification (extension of diverticulosis, number of diverticula, presence and type of inflammation, and the presence and type of complications) that could predict the outcome of the disease and possibly be helpful to guide the indications for elective surgery. ${ }^{44}$

\section{Colonic perforation: laparoscopic lavage vs nonoperative treatment}

At the end of the 20th century two new treatments of perforated colonic diverticulitis have been described. In 1996, O'Sullivan et a ${ }^{45}$ reported their first eight patients with purulent generalized peritonitis treated between 1991 and 1994 by laparoscopic lavage, whereas Dharmarajan et a ${ }^{46}$ reported in 2011 their experience of nonoperative management of acute complicated diverticulitis with 25 of 27 patients (92.5\%), having distant free air remote from the perforation site, who were successfully treated nonoperatively from 1995 to 2008.

The main difference between these two therapeutic concepts is the fact that the nonoperative approach is thoroughly based on CT results, whereas the laparoscopic approach is based on a surgical appreciation where patients were reported as having a "generalized purulent peritonitis". There is no doubt that the latter surgical definition might include a great variation in clinical presentations, which renders more difficult the analysis of this technique.

Today, besides Dharmarajan's report, three studies have published their experience of nonoperative treatment of colonic perforation in hemodynamically stable patients. The rate of success of conservative treatment was between $60 \%$ and $80.5 \%$ for distant peritoneal air and between $62 \%$ and $100 \%$ for free peritoneal fluid. ${ }^{47-49}$ Regarding the experience of laparoscopic lavage and drainage, of 17 studies including 873 patients, three were prospective and six included $<10$ patients. Only 446 patients $(51 \%)$ were classified according to Hinchey's stages: four patients (1\%) were Hinchey 1, 78 patients $(17 \%)$ were Hinchey 2, 342 patients $(77 \%)$ were Hinchey 3, and 22 patients $(5 \%)$ were Hinchey 4. Postoperative morbidity was $0 \%-54 \%$, mortality was $0 \%-6 \%$, and surgical reoperations were $0 \%-19 \%$. The lack of homogeneity of these postoperative results speaks for a poor quality of the existing current literature. ${ }^{45,50-66}$ The results of three multicenter randomized studies including patients with purulent peritonitis (Hinchey 3) have now been published. In the first study, the DILALA trial published in 2016, 75 patients were available for analysis (39 in the laparoscopic lavage group and 36 in the Hartmann group) and were randomized. Reoperation within 30 days was equivalent (13.2\% after laparoscopic lavage vs $13.2 \%$ after Hartmann operation). As morbidity and mortality after laparoscopic lavage did not differ compared with the Hartmann procedure and that laparoscopic lavage resulted in shorter operating time, shorter time in the recovery unit, and shorter hospital stay, the authors concluded that laparoscopic lavage was feasible and safe in the short-term. ${ }^{67}$ We should though take these results with caution considering the low number of selected patients, the exclusion of $\sim 50 \%$ of potential candidates without clear reasons, and the highly statistical difference in the presence of visible perforation $(5.2 \%$ for the laparoscopic 
lavage and $50 \%$ for the Hartmann, $P<0.0001$ ) that authors attributed to the handling of the colon during the open Hartmann procedure. Moreover, the $17.1 \%$ rate of early reoperation after Hartmann procedure seems to be quite high compared with the following two randomized studies ( $7 \%$ for the second study ${ }^{68}$ and $5.7 \%$ for the third study ${ }^{69}$ ) and with the French randomized study of primary colonic resection vs proximal colostomy + drainage that reported a $3.6 \%$ rate of early reoperation after primary resection. ${ }^{70}$ The second study, the LOLA group of the Ladies trial, included 90 patients. The trial had to be ended as the safety of the participants in the lavage group was at risk considering the high rate of surgical inhospital reoperation after lavage (18 patients (39\%) in the lavage group vs two patients (5\%) in the sigmoidectomy group). By 12 months, four patients had died after lavage and six patients had died after sigmoidectomy. The authors concluded that laparoscopic lavage was not superior to sigmoidectomy. ${ }^{68}$ The Scandinavian randomized study included 101 patients with laparoscopic lavage vs 98 with primary resection. The early reoperation rate was $20.3 \%$ for the laparoscopic lavage and $5.7 \%$ for the Hartmann procedure. Moreover, four sigmoid carcinomas were missed with laparoscopic lavage. The authors concluded that these findings did not support laparoscopic lavage for the treatment of perforated diverticulitis. ${ }^{69}$ These controversial results do not bring a clear light about indications and identification of patients who would benefit from laparoscopic lavage and drainage for perforated diverticulitis with purulent peritonitis. ${ }^{71}$ In his Editorial about indications for laparoscopic lavage and drainage, Mutch (cowriter of Dharmarajan's study ${ }^{46}$ ), underlined the lack of comparative studies to endorse this technique. He thinks that, "with appropriate percutaneous drainage, antibiotic therapy, nutrition, and clinical support, many of these patients could have been successfully treated without urgent operation"72

Unfortunately, the numerous publications about laparoscopic lavage and even the expected results of the three randomized studies did not shed light on the place of laparoscopic lavage. The highly different rates of postoperative morbidity $(0 \%-54 \%)$, mortality $(0 \%-6 \%)$, and surgical reoperations $(0 \%-19 \%)$ of the 17 first publications and the same findings for the three randomized studies (mortality 3\%-13.5\%/surgical reoperations 13.2\%-28\%) show that the place of laparoscopic is still far from being clear, and that, consequently, surgeons should stay on the wise side of the surgical choice (colectomy with anastomosis \pm ileostomy or Hartmann) if they find a visible colonic hole, a diffuse peritonitis or for patients with co-morbidity.

\section{Recurrent diverticular diseases}

A few years ago, a growing body of knowledge has shown that acute diverticulitis might turn into a chronic bowel disorder composed of recurrent abdominal symptoms and considerable psychosocial impact. New research implicates a role for low-grade inflammation, sensorymotor nerve damage, and dysbiosis in a clinical picture that mimics irritable bowel syndrome (IBS) and even inflammatory bowel disease. ${ }^{73}$ For the last few years, two chronic different syndromes related to diverticular disease have been identified besides the classical presentations of diverticulitis. The first condition is known as "symptomatic uncomplicated diverticular disease (SUDD)"74 or "uncomplicated symptomatic diverticular disease (SYMPDD)", ${ }^{75}$ and the second condition is known as "IBS-like diverticular disease". ${ }^{74,76}$ In the first condition (SYMP-DD), the pain is longer ( $>24$ hours), not relieved by defecation, localized in the left iliac fossa, diarrhea is more frequent, often associated with fever, with a raised white count, and positive fecal calprotectin. For these cases, CT scan should be done to confirm an acute diverticulitis. "IBS-like diverticular disease" is determined by recurrent, shortlived, diffused low abdominal pain and bloating relieved by defecation, diarrhea is not prominent, and bioclinical signs of inflammation are normal. Moreover, the "IBS-like syndrome" was not existing before diverticular disease. If this presentation appears closer to IBS, when the strict Rome I criteria were applied only $15 \%$ met these criteria. We now know that about one third of patients with previous confirmed episode(s) of acute diverticulitis will have recurrent abdominal pain and disturbed bowel habit. ${ }^{77}$ After acute diverticulitis inflammatory response and ingress of white blood cells are likely to damage enteric nerves leading to altered neuropeptide distribution and may well induce visceral hypersensitivity (somatization) that can be assessed by a Personal Health Questionnaire (PHQ12-SS). ${ }^{78}$ Somatization appears to reflect abnormal central pain processing that renders difficult to define the role of the diverticular disease. Patients with a high somatization may respond to antidepressants, cognitive behavior, or brain-directed therapies, while patients with a low score may well respond to mesalazine, rifaximin, or probiotics and possibly to surgery. ${ }^{75}$ Interesting enough is the retrospective experience of the Mayo Clinic reported by Wolff and Boostrom ${ }^{80}$ on 684 patients, with a median (range) of 1.68 years, who underwent elective surgery for uncomplicated diverticulitis between 2005 and 2009. Five hundred and sixty-four patients $(82 \%)$ were classified as "acute resolving diverticulitis", 54 patients $(8 \%)$ were 
classified as "atypical diverticular disease", and 66 patients $(10 \%)$ were classified as "chronic or smoldering diverticulitis". Acute resolving episodes of diverticulitis represent the most common presentation with left iliac pain, fever, clinical localized tenderness, leukocytosis, and increased CRP. CT scan confirms the diagnosis of acute diverticulitis. Patients with "chronic or smoldering diverticulitis" have the same symptoms, fever, leukocytosis, and either do not improve with antibiotic treatment or show a rebound symptomatology at the end of treatment with continuing inflammation. These patients have refractory inflammation. The patients with "atypical diverticulitis" present primarily with pain and may report alterations in bowel habits, though without fever, leukocytosis, or radiological signs of diverticulitis. This atypical presentation has similarity to IBS with the difference that symptoms occur at $\sim 60$ years together with diverticular disease when the peak of real IBS happens in the early 1920s and 1930s. Following elective surgery, $59(89 \%)$ of the 66 patients with "chronic/smoldering diverticular disease" reported complete resolution of symptoms, whereas 50 (93\%) of the 54 patients with "atypical diverticular disease" reported complete resolution of symptoms. ${ }^{79,80}$ These two surgical entities show a clear relation with the two conditions previously reported: "chronic/smoldering diverticular disease" has similarity with SYMP-DD or SUDD while "atypical diverticular disease" compares to IBS-like diverticular disease. It is then reasonable to consider surgical treatment for the patients with SYMP-DD or SUDD and for the patients with IBSlike diverticular disease showing low somatization (low psychometric score using $\mathrm{PHQ}-12 \mathrm{SS}^{78}$ ) not responding to conservative treatment.

As early as 25 years ago, Moreaux et $\mathrm{al}^{81}$ reported longterm very good results in $82 \%$ of the 72 patients operated on for chronic symptoms and suggested that chronic symptoms should be taken into account with respect to surgical indications.

\section{Hinchey's surgical classification is now outdated}

In 1963 , Hugues et al ${ }^{82}$ reported the first clinical classification of acute colonic diverticulitis that did not remain as a reference in the literature. In 1978, Hinchey et $\mathrm{al}^{32}$ published a new four-stage classification based on surgical findings (pericolic abscess or phlegmon/pelvic, intra-abdominal, or retroperitoneal abscess/general purulent peritonitis/fecal peritonitis). Since then, this classification has been modified several times as reported by the
Table 2 Revised clinical classification

I. Uncomplicated diverticulitis
Phlegmonous diverticulitis
2. Complicated diverticulitis
2.I. Abscess
Site(s)
Mesenteric
Pelvic
Abdominal
Size (cm)
2.2. Colonic perforation
Mesenteric
Peritoneal
Localized purulent peritonitis
Generalized purulent peritonitis
Fecal peritonitis
3. Recurrent diverticular disease
Recurrent episode(s) of acute diverticulitis
4. Recurrent symptomatic diverticular disease
4.I. Irritable bowel syndrome-like diverticular disease
4.2. Symptomatic uncomplicated diverticular disease
5. Chronic diverticulitis
5.I. Fistula
5.2. Stenosis

publication of Klarenbeek et al ${ }^{83}$ Hinchey's classification is divided into two parts: abscess(es) (stages 1-2), the treatment of which is now well codified, and generalized purulent or fecal peritonitis (stages 3 and 4 ) that requires a surgical treatment. This classification is now insufficient to cover all the presentations of acute colonic diverticulitis. There is indeed a missing gap between these two compartments: colonic perforation with intramesentericor peritoneal air and/or fluid, which could eventually be treated nonoperatively.

Logically, the clinical classification should be based on the detailed findings brought by the CT scan and be independent of Hinchey's stages. This classification should hold four main chapters: uncomplicated, complicated, recurrent, and chronic diverticulitis. Each chapter should contain the different pathological elements characteristic of the chapter (Table 2).

\section{Conclusion}

In our experience, CT scan should always be realized when clinical and biological findings are suggesting the diagnosis of acute left colonic diverticulitis. This added imaging confirms the suspected diagnosis of acute diverticulitis and states precisely the severity of the disease (uncomplicated vs complicated diverticulitis) in order to guide the therapeutic issues and to better define the risk of recurrence. Moreover, CT scan will assist the surgeon, in case of elective surgery, 
to remove part of the distal descending colon whenever acute diverticulitis was located at this part of the colon.

For hemodynamically stable patients with colonic perforation, laparoscopic lavage is a therapeutic choice between conservative treatment and sigmoidectomy. Its place is not yet well defined. Here again, higher quality preoperative CT scan using rectal contrast could bring important findings (diffuse contrast in the abdominal cavity and suspicion of colon cancer) that might indicate that lavage would not be suitable.

Surgical option for patients with chronic symptomatic diverticular disease not responding to conservative treatment seems to have a growing place.

Finally, the proposed CT scan and clinical classifications have been dissociated and simplified according to the evolving knowledge about diverticular disease.

\section{Acknowledgment}

The author had no funding support and financial relationship.

\section{Disclosure}

The author reports no conflicts of interest in this work.

\section{References}

1. Shahedi K, Fuller G, Bolus R, et al. Long-term risk of acute diverticulitis among patients with incidental diverticulosis found during colonoscopy. Clin Gastroenterol Hepatol. 2013;11(12):1609-1613.

2. Peery AF, Barrett PR, Park D, et al. A high-fiber diet does not protect against asymptomatic diverticulosis. Gastroenterology. 2012;142(2):266.e1-272.e1.

3. Anaya DA, Flum DR. Risk of emergency colectomy and colostomy in patients with diverticula disease. Arch Surg. 2005;140(7): $681-685$

4. Rose J, Parina RP, Faiz O, Chang DC, Talamini MA. Long term outcomes after initial presentation of diverticulitis. Ann Surg. 2015;262(6): 1046-1053.

5. Nguyen GC, Sam J, Anand N. Epidemiological trends and geographic variation in hospital admissions for diverticulitis in the United States. World J Gastroenterol. 2011;17(12):1600-1605.

6. Strate LL, Peery AF, Neumann I. American Gastroenterological Association Institute Technical Review on the management of acute diverticulitis. Gastroenterology. 2015;149(7):1950-1976.

7. Andeweg CS, Wegdam JA, Groenewoud J, van der Wilt GJ, van Goor H, Bleichrodt RP. Toward an evidence-based step-up approach in diagnosing diverticulitis. Scand J Gastroenterol. 2014;49(7): 775-784.

8. Andeweg CS, Knibben L, Hendriks JC, Bleichrodt RP, Van Goor H. How to diagnose acute left-sided colonic diverticulitis: proposal for a clinical scoring system. Ann Surg. 2011;253(5):940-946.

9. Karidis NP, Dimitroulis D, Kouraklis G. The role of abdominal imaging in cases with a high probability of acute left-sided colonic diverticulitis based on a clinical scoring system. Ann Surg. 2013;258(2):e14.

10. Rao PM, Rhea JT, Novelline RA, et al. Helical CT with only colonic contrast material for diagnosing diverticulitis: prospective evaluation of 150 patients. AJR Am J Roentgenol. 1998;170(6): 1445-1449.
11. Ambrosetti P, Becker C, Terrier F, et al. Colonic diverticulitis: impact of imaging on surgical management - a prospective study of 542 patients. Eur Radiol. 2002;12(5):1145-1149.

12. Ambrosetti P, Jenny A, Becker C, Terrier TF, Morel P. Acute left-colonic diverticulitis: compared performance of computed tomography and water-soluble contrast: prospective evaluation of 420 patients. Dis Colon Rectum. 2000;43(10):1363-1367.

13. Feingold D, Steele SR, Lee S, et al. Practice parameters for the treatment of sigmoid diverticulitis. Dis Colon Rectum. 2014;57(3):284-294.

14. Laméris W, Van Randen A, Van Gulik TM, et al. A clinical decision rule to establish the diagnosis of acute diverticulitis at the emergency department. Dis Colon Rectum. 2010;53(6):896-904.

15. Laurell H, Hansson LE, Gunnarsson U. Acute diverticulitis-clinical presentation and differential diagnostics. Colorectal Dis. 2007;9:496-501.

16. Kiewet JS, Andeweg CS, Laurell H, et al. External validation of two tools for the clinical diagnosis of acute diverticulitis without imaging. Dig Liver Dis. 2014;46(2):119-124.

17. Longstreth GF, Lyer RL, Chu LH, et al. Acute diverticulitis: demographic, clinical and laboratory features associated with computed tomography findings in 741 patients. Aliment Pharmacol Ther. 2012;36(9):886-894.

18. Toorenvliet BR, Bakker RFR, Breslau PJ, Merkus JWS, Hamming JF. Colonic diverticulitis: a prospective analysis of diagnostic accuracy and clinical decision-making. Colorectal Dis. 2010;12(3):179-186.

19. Käser SA, Fankhauser G, Glauser PM, Toia D, Maurer CA. Diagnostic value of inflammation markers in predicting perforation in acute sigmoid diverticulitis. World J Surg. 2010;34(11):2717-2722.

20. van de Wall BJM, Draaisma WA, van der Kaaij RT, Consten EC, Wiezer MJ, Broeders IA. The value of inflammation markers and body temperature in acute diverticulitis. Colorectal Dis. 2012;15(5):621-626.

21. Vennix S, Morton DG, Hahnloser D, Lange JF, Bemelman WA; Research Committee of the European Society of Coloproctology. Systematic review of evidence and consensus on diverticulitis: an analysis of national and international guidelines. Colorectal Dis. 2014;16(11):866-878.

22. O'Connor ES, Leverson G, Kennedy G, Heise CP. The diagnosis of diverticulitis in outpatients: on what evidence? J Gastrointest Surg. 2010;14(2):303-308.

23. Trenti L, Kreisler E, Galvez A, Golda T, Frago R, Biondo S. Long-term evolution of acute colonic diverticulitis after successful medical treatment. World J Surg. 2015;39(1):266-274.

24. Ambrosetti P, Grossholz M, Becker C, Terrier F, Morel PH. Computed tomography in acute left-colonic diverticulitis. Br J Surg. 1997;84(4):532-534.

25. Poletti PA, Platon A, Rutschmann O, et al. Acute left-colonic diverticulitis: can CT findings be used to predict recurrence? AJR Am J Roentgenol. 2004;182(5):1159-1165.

26. Shaikh S, Krukowski ZH. Outcome of a conservative policy for managing acute sigmoid diverticulitis. Br J Surg. 2007;94(7):876-879.

27. Hall JF, Roberts PL, Ricciardi R, et al. Long-term follow-up after an initial episode of diverticulitis: what are the predictors of recurrence? Dis Colon Rectum. 2011;54(3):283-288.

28. Buchs NC, Konrad-Mugnier B, Jannot AS, Poletti PA, Ambrosetti P, Gervaz P. Assessment of recurrence and complications following uncomplicated diverticulitis. Br J Surg. 2013;100(7):976-979.

29. Gervaz P, Platon A, Widmer L, Ambrosetti P, Poletti PA. A clinical and radiological comparison of sigmoid diverticulitis episodes 1 and 2. Colorectal Dis. 2012;14(4):463-468.

30. Ambrosetti P, Gervaz P. Laparoscopic elective sigmoidectomy for diverticular disease: a plea for standardization of the procedure. Colorectal Dis. 2014;16(2):90-94.

31. Flor N, Maconi G, Cornalba G, Pickhardt PJ. The current role of radiologic and endoscopic imaging in the diagnosis and follow-up of colonic diverticular disease. AJR Am J Roentgenol. 2016;207(1): $15-24$.

32. Hinchey EJ, Schaal PG, Richards GK. Treatment of perforated diverticular disease of the colon. Adv Surg. 1978;12:85-109. 
33. Gielens MPM, Mulder IM, van der Harst E, et al. Preoperative staging of perforated diverticulitis by computed tomography scanning. Tech Coloproctol. 2012;16(5):363-368.

34. Rao PM, Rhea JT, Novelline RA, et al. Helical CT with only colonic contrast material for diagnosing diverticulitis: prospective evaluation of 150 patients. AJR Am J Roentgenol. 1998;170(6):1445-1449.

35. Kircher MF, Rhea JT, Kihiczak D, Novelline RA. Frequency, sensitivity and specificity of individual signs of diverticulitis on thin-section helical CT with colonic contrast material: experience with 312 cases. AJR Am J Roentgenol. 2002;178(6):1313-1318.

36. Buckley O, Geoghegan T, O'Riordain DS, Lyburn ID, Torreggiani WC. Computed tomography in the imaging of colonic diverticulitis. Clin Radiol. 2004;59(11):977-983.

37. Lohrmann C, Ghanem N, Pache G, Makowiec F, Kotter E, Langer M. CT in acute perforated sigmoid diverticulitis. Eur J Radiol. 2005;56(1): $78-83$.

38. DeStigter KK, Keating DP. Imaging update: acute colonic diverticulitis. Clin Colon Rectal Surg. 2009;22(3):147-155.

39. Hammond NA, Nikolaidis P, Miller FH. Left lower-quadrant pain: guidelines from the American College of Radiology Appropriateness Criteria. Am Fam Physician. 2010;82(7):766-770.

40. Ben Yaacoub I, Boulay-Coletta I, Jullès MC, Zins M. CT findings of misleading features of colonic diverticulitis. Insights Imaging. 2011;2(1): 69-84.

41. Tursi A. The role of colonoscopy in managing diverticular disease of the colon. J Gastrointestin Liver Dis. 2015;24(1):85-93.

42. Flor N, Maconi G, Sardanelli F, et al. Prognostic value of the diverticular disease severity score based on CT colonography. Followup in patients recovering from acute diverticulitis. Acad Radiol. 2015;22(12):1503-1509.

43. Tursi A, Brandimarte G, Di Mario F, et al. Development and validation of an endoscopic classification of diverticular disease of the colon: the DICA classification. Dig Dis. 2015;33(1):68-76.

44. Tursi A. Why perform colonoscopy following acute diverticulitis of the colon ? Surg Endosc. 2014;28(11):3260-3262.

45. O'Sullivan GC, Murphy D, O’Brien MG, Ireland A. Laparoscopic management of generalized peritonitis due to perforated colonic diverticula. Am J Surg. 1996;171(4):432-434.

46. Dharmarajan S, Hunt SR, Birbaun EH, Fleshman JW, Mutch MG. The efficacy of nonoperative management of acute complicated diverticulitis. Dis Colon Rectum. 2011;54(6):663-671.

47. Costi R, Cauchy F, Le Bian A, Honart JF, Creuze N, Smadja C. Challenging a classic myth: pneumoperitoneum associated with acute diverticulitis is not an indication for open or laparoscopic emergency surgery in hemodynamically stable patients. A 10-year experience with a nonoperative treatment. Surg Endosc. 2012;26(7):2061-2071.

48. Bandera BC, Strode M, Rice R. Nonoperative management of complicated diverticulitis with extradigestive air. Am Surg. 2013;79(6):E243-E245.

49. Sallinen VJ, Mentula PJ, Leppäniemi AK. Nonoperative management of perforated diverticulitis with extraluminal air is safe and effective in selected patients. Dis Colon Rectum. 2014;57(7):875-881.

50. Faranda C, Barrat C, Catheline JM, Champault GG. Two-stage laparoscopic management of generalized peritonitis due to perforated sigmoid diverticula: eighteen cases. Surg Laparosc Endosc Percutan Tech. 2000;10(3):135-138.

51. Da Rold AR, Guerriero S, Fiamingo P, et al. Laparoscopic colorrhapy, irrigation and drainage in the treatment of complicated acute diverticulitis: initial experience. Chir Ital. 2004;56(1):95-98.

52. Taylor CJ, Layani L, Ghusn MA, White SI. Perforated diverticulitis managed by laparoscopic lavage. ANZ J Surg. 2006;76(11):962-965.

53. Mutter D, Bouras G, Forgione A, Vix M, Leroy J, Marescaux J. Two-stage totally mini-invasive approach for acute complicated diverticulitis. Colorect Dis. 2006;8:501-505.

54. Galleano R, Di Giorgi S, Franceschi A, Falchero F. Two-stage laparoscopic management of complicated acute diverticulitis: initial experience. Ann Ital Chir. 2007;78(1):61-64.
55. Myers E, Hurley M, O’Sullivan GC, Kavanagh G, Wilson I, Winter DC. Laparoscopic peritoneal lavage for generalized peritonitis due to perforated diverticulitis. Br J Surg. 2008;95(1):97-101.

56. Bretagnol F, Pautrat K, Mor C, Benchellal Z, Huten N, de Calan L. Emergency laparoscopic management of perforated sigmoid diverticulitis: a promising alternative to more radical procedure. $\mathrm{J} \mathrm{Am} \mathrm{Coll}$ Surg. 2008;206(4):654-657.

57. Franklin ME Jr, Portillo G, Trevino JM, Gonzalez JJ, Glass JL. Long-term experience with the laparoscopic approach to perforated diverticulitis plus generalized peritonitis. World J Surg. 2008;32(7): $1507-1511$.

58. Mazza D, Chio F, Khoury-Helou A. Conservative laparoscopic treatment of diverticular peritonitis. J Chir (Paris). 2009;146(3):265-269.

59. Lam HD, Tinton N, Cambier E, Navez B. Laparoscopic treatment in acute complicated diverticulitis: a review of 11 cases. Acta Chir Belg. 2009;109(1):56-60.

60. Favuzza J, Friel JC, Kelly JJ, Perugini R, Counihan TC. Benefits of laparoscopic peritoneal lavage for complicated sigmoid diverticulitis. Int J Colorectal Dis. 2009;24(7):797-801.

61. Karoui M, Champault A, Pautrat K, Valleur P, Cherqui D, Champault G. Laparoscopic lavage or primary anastomosis with defunctioning stoma for Hinchey 3 complicated diverticulitis: results of a comparative study. Dis Colon Rectum. 2009;52(4):609-615.

62. White SI, Frenkiel B, Martin PJ. A ten-year audit of perforated sigmoid diverticulitis: highlighting the outcomes of laparoscopic lavage. Dis Colon Rectum. 2010;53(11):1537-1541.

63. Rogers AC, Collins D, O'Sullivan GC, Winter DC. Laparoscopic lavage for perforated diverticulitis: a population analysis. Dis Colon Rectum. 2012;55(9):932-938.

64. Swank HA, Mulder IM, Hoofwijk AGM, Nienhuijs SW, Lange JF, Bemelman WA. On behalf of the Dutch Diverticular Disease Collaborative Study Group. Early experience with laparoscopic lavage for perforated diverticulitis. Br J Surg. 2013;100(5):704-710.

65. Radé F, Bretagnol F, Auguste M, Di Guisto C, Huten N, de Calan L. Determinants of outcome following laparoscopic peritoneal lavage for perforated diverticulitis. Br J Surg. 2014;101(12):1602-1606.

66. Rossi GL, Mentz R, Bertone S, et al. Laparoscopic peritoneal lavage for Hinchey III diverticulitis: is it as effective as it is applicable ? Dis Colon Rectum. 2014;57(12):1384-1390.

67. Angenete E, Thornell A, Burcharth J, et al. Laparoscopic lavage is feasible and safe for the treatment of perforated diverticulitis with purulent peritonitis. The first results from the randomized controlled trial DILALA. Ann Surg. 2016;263(1):117-122.

68. Vennix S, Musters GD, Mulder IM, et al. Laparoscopic peritoneal lavage or sigmoidectomy for perforated diverticulitis with purulent peritonitis: a multicentre, parallel-group, randomised, open-label trial. Lancet. 2015;386(10000):1269-1277.

69. Schultz JK, Yaqub S, Wallon C, et al. Laparosopic lavage vs primary resection for acute perforated diverticulitis. The Scandinav randomized clinical trial. JAMA. 2015;314(13):1364-1375.

70. Zeitoun G, Laurent A, Rouffet F, et al. Multicentre, randomized clinical trial of primary vs secondary sigmoid resection in generalized peritonitis complicating sigmoid diverticulitis. Br J Surg. 2000;87: $1366-1374$.

71. Mc Dermott FD, Collins D, Heeney A, Winter DC. Minimally invasive and surgical management strategies tailored to the severity of acute diverticulitis. Br J Surg. 2014;101(1):e90-e99.

72. Mutch MG. Complicated diverticulitis: are there indications for laparoscopic lavage and drainage? Dis Colon Rectum. 2010;53(11):1465-1466.

73. Strate LL, Modi R, Cohen E, Brennan MR, Spiegel MR. Diverticular disease as a chronic illness: evolving epidemiologic and clinical insights. Am J Gastroenterol. 2012;107(10):1486-1493.

74. Tursi A, Elisei W, Picchio M, et al. Moderate to severe and prolonged left-lower abdominal pain is the best symptom characterizing symptomatic uncomplicated diverticular disease of the colon. J Clin Gastroenterol. 2015;49(3):218-221. 
75. Spiller R. Is it diverticular disease or is it irritable bowel disease syndrome? Dig Dis. 2012;30:64-69.

76. Spiller R. Editorial: new thoughts on the association between diverticulosis and irritable bowel syndrome. Am J Gastroenterol. 2014; 109(12):1906-1908.

77. Simpson J, Neal KR, Scholefield JH, Spiller R. Patterns of pain in diverticular disease and the influence of acute diverticulitis. Eur $J$ Gastroenterol Hepatol. 2003;15(9):1005-1010.

78. Spiller RC, Humes DJ, Campbell E, et al. The Patient Health Questionnaire 12 Somatic Symptom scale as a predictor of symptom severity and consulting behavior in patients with irritable bowel syndrome and symptomatic diverticular disease. Aliment Pharmacol Ther. 2010;32(6):811-820.
79. Boostrom SY, Wolff BG, Cima RR, Merchea A, Dozois EJ, Larson DW. Uncomplicated diverticulitis: more complicated than we thought. J Gastrointest Surg. 2012;16(9):1744-1749.

80. Wolff BG, Boostrom SY. Prophylactic resection, uncomplicated diverticulitis, and recurrent diverticulitis. Dig Dis. 2012;30(1):108-113.

81. Moreaux J, Vons C. Elective resection for diverticular disease of the sigmoid colon. Br J Surg. 1990;77(9):1036-1038.

82. Hugues ES, Cuthbertson AM, Carden AB. The surgical management of acute diverticulitis. Med J Aust. 1963;50:780-782.

83. Klarenbeek BR, de Korte N, van der Peet DL, Cuesta MA. Review of current classifications for diverticular disease and a translation into clinical practice. Int J Colorectal Dis. 2012;27:207-214.

\section{Clinical and Experimental Gastroenterology}

\section{Publish your work in this journal}

Clinical and Experimental Gastroenterology is an international, peerreviewed, open access, online journal publishing original research, reports, editorials, reviews and commentaries on all aspects of gastroenterology in the clinic and laboratory. This journal is included on PubMed. The manuscript management system is completely online

\section{Dovepress}

and includes a very quick and fair peer-review system, which is all easy to use. Visit http://www.dovepress.com/testimonials.php to read real quotes from published authors. 